the focus of a system of lenses, so that the rays may cross in the interior of the prism. This is an unfavourable position for a prismatic analyser, and in the case of a powerful beam of light, such as that from the electric arc, the crossing of the rays within the prism is not unattended with danger to the cementing substance, and to the surfaces in contact with it.

Philip R. Sleeman

\section{ON VARIOUS SUGGESTIONS AS TO THE SOURCE OF ATMOSPHERIC ELECTRICITY ${ }^{1}$}

$W^{\mathrm{E}}$ have seen that, taking for granted the electrification of clouds, all the ordinary phenomena of a thunderstorm (except globe lightning) admit of easy and direct explanation by the known laws of statical electricity. Thus far we are on ccmparatively sure ground.

But the case is very different when we attempt to look a little farther into the matter, and to seek the source of atmospheric electricity. One cause of the difficulty is easily seen. It is the scale on which meteorological phenomena usually occur; so enormously greater than that of any possible laboratory arrangement that effects, which may pass wholly unnoticed by the most acute experimenter, may in nature rise to paramount importance. I shall content myself with one simple but striking instance.

Few people think of the immense transformations of energy which accompany an ordinary shower. But a very easy calcula. tion leads us to startling results. To raise a single pound of water, in the form of vapour, from the sea or from moist ground, requires an amount of work equal to that of a horse for about half an hour! This is given out again, in the form of heat, by the vapour when it condenses; and the pound of water, falling as rain, would cover a square foot of ground to the depth of rather less than one-fifth of an inch. Thus a fifth of an inch of rain represents a horse-power for half an hour on every square foot ; or, on a square mile, about a million horse-power for fourteen hours! A million horses would barely have standing room on a square mile. Considerations like this show that we can account for the most violent hurricanes by the energy set free by the mere condensation of vapour required for the concomitant rain.

Now the modern kinetic theory of gases shows that the particles of water-va pour are so small that there are somewhere about three hundred millions of millions of millions of them in a single cubic inch of saturated steam at ordinary atmospheric piessure. This corresponds to $1 / 1600$ or so of a cubic inch of water, i.e. to about an average raindrop. But if each of the vapour particles had been by any cause electrified to one and the same potential, and all could be made to unite, the potential of the raindrop formed from them would be fifty million million times greater.

Thus it appears that if there be any cause which would give each particle of vapour an electric potential, even if that potential were far smaller than any that can be indicated by our most delicate electrometers, the aggregation of these particles into raindrops would easily explain the charge of the most formidable thundercloud. Many years ago it occurred to me that the mere contact of the particles of vapour with those of air, as they interdiffuse according to the kinetic theory of gases, would suffice to produce the excessively small potential requisite. Thus the source of atmospheric electricity would be the same as that of Volta's electrification of dry metals by contact. My experiments were all made on a small scale, with ordinary laboratory apparatus. Their general object was, by various processes, to precipitate vapour from damp air, and to study either (I) the electrification produced in the body on which the vapour was precipitated; or (2) to find on which of two parallel, polished plates, oppositely electrified and artificially cooled, the more rapid deposition of moisture would take place. After many trials, some resultless, others of a more promising character, I saw that experiments on a comparatively large scale would be absolutely necessary in order that a definite answer might be obtained. I communicated my views to the Royal Society of Edinburgh in 1875 , in order that some one with the requisite facilities might be induced to take up the inquiry, but I am not aware that this has been done.

I may briefly mention some of the more prominent attempts which have been made to solve this curious and importan problem. Some of them are ludicrous enough, but their diversity well illustrates the nature and amount of the difficulty.

x By Prof. Tait. Read at the meeting of the Scottish Meteorologica Society on March ${ }_{7}$, and communicated by the Society.
The oldest notion seems to have been that the source of atmospheric electricity is aërial friction. Unfortunately for this theory, it is not usually in windy weather that the greatest development of electricity takes place.

In the earlier years of this century Pouillet claimed to bave established by experiment that in all cases of combustion or oxidation, in the growth of plants, and in evaporation of salt water, electricity was invariably developed. But more recent experiments have thrown doubt on the first two conclusions, and have shown that the third is true only when the salt water is boiling, and that the electricity then produced is due to friction, not to evaporation. Thus Faraday traced the action of Armsirong's hydro-electric machine to friction of the steam against the orifice by which it escaped.

Saussure and others attributed the production of atmospheric electricity to the condensation of vapour, the reverse of one of Pouillet's hypotheses. This, however, is a much less plausible guess than that of Pouillet; for we could understand a particle of vapour carrying positive electricity with it, and leaving an equal charge of negative electricily in the water from which it escaped. But to account for the separation of the two electricities when two particles of vapour unite is a much less promising task.

Peltier (followed by Lamont) assumed that the earth itself has a permanent charge of negative electricity whose distribution varies from time to time, and from place to place. Air, according to this hypothesis, can neither hold nor conduct electricity, but a cloud can do both; and the cloud is electrified by conduction if it touch the earth, by induction if it do not. But here the difficulty is only thrown back one step. How are we to account for the earth's permanent charge?

Sir W. Thomson starts from the experimental fact that the layer of air near the ground is often found to be strongly electrified, and accounts for atmospheric electricity by the carrying up of this layer by convection currents. But this process also only shifts the difficulty.

A wild theory has in recent times been proposed by Becquerel. Corpuscles of some kind, electrified by the outbursts of glowing hydrogen, travel from the sun to the upper strata of the earth's atmosphere.

Muihry traces the source of electricity to a direct effect of solar radiation falling on the earth's surface.

Liuddens has recently attributed it to the friction of aqueous vapour against dry air. Some still more recent assumptions attribute it to capillary surface-tension of water, to the production of hail, \&c.

Blake, Kalischer, \&c., have lately endeavoured to show by experiment that it is not due to evaporation, or to condensation of water. Their experiments, however, have all been made on too small a scale to insure certain results. What I have just said about the extraordinary number of vap ur particles in a single raindrop, shows that the whole charge in a few cubic feet of moist air may altogether escape detection.

And so the matter will probably stand, until means are found of making these delicate experiments in the only way in which success is likely to be obtained, viz. on a scale far larger than is at the command of any ordinary private purse. It is a question of real importance, not only for pure science but for the people, and ought to be thoroughly sifted by means which only a wealthy nation can provide.

\section{UNIVERSITY AND EDUCATIONAL}

\section{INTELLIGENCE}

CAMBRIDGE.-The General Board of Studies propose to appoint, early in Easter Term, a number of Readers and University Lecturers, including the following: a Reader in Comparative Philology, stipend $300 l$. per annum; a Reader in B tany, stipend 10ol. ; University Lecturers in Sanskrit, in Comparative Philology, in Mathematics (one in each group of the Tripos, Part 3), in Applied Mechanics, in Botany, in Animal Morphology, in Advanced Physiology (three), in Geology, in History (five), and in Moral Science; all at 5ol., except in Animal Morphology and in Geology, to which rool. is assigned. The University Lecturers will for the most part be chosen from such College Lecturers as open their lectures to the University ge ierally; but the Board is not necessarily restricted to such; nor to persons who may apply. Candidates are to send in their names and testimonials (if any) to the Vice-Chancellor not later than April 25. It is understood that two lectures a week during 